extensor group. Lesions of the cerebrum and pyramidal tracts are much more often followed by rigidity of muscle than any lesion situated elsewhere. It is impossible, in the present state of our knowledge, to make any definite assertions as to the physiology of rigidity, but, speaking broadly, we know that diseases limited to the reflex arcs of the spinal cord do not per se produce rigidity. It seems most probable that the exaggerations of muscular action in phthisis and typhoid fever should be attributed to an increased irritability, not only of the muscular tissue itself, but also of the nervous components of the reflex arcs of the spinal cord. Since ankle clonus may appear and disappear in continued fevers, it would seem certain that the foot phenomenon is not always dependent on lateral sclerosis of the spinal cord. Indeed such a proposition, though still held by some neurologists, has long ago been rejected by others. Further, sclerotic tissue in and of itself can produce no symptoms, for it is al together outside the nervous system, and it only produces symptoms indirectly by its action on the genuine nervous protoplasm. It would be strange indeed if that condition of the neuro-muscular protoplasm on which ankle clonus depends could not be broughtabout by changes other than those induced by sclerosis of the pyramidal tracts. Cases of peripheral and spinal and cerebral paralysis have been recorded as occurring during and after typhoid fever. But the changes to which I refer are to be met with in all cases of typhoid fever which have had considerable fever lasting for more than ten days. It seems to me that such deviations from the normal that I have described can only be attributed to general disturbance of the nutrition of the nervous and muscular apparatus. As has so often been pointed out by various authors since the time of Todd, "movements" are next door to paralysis. No case of hyperkinesis occurs without some weakness, and excessive action is a sign, not of strength, but of disease. "Irritable weakness" is the best name for this phenomenon, which is illustrated in delirium, chorea, and the various other forms of over-action. The excessive action of Carlyle's diction was but the strength of irritable weakness; and all forms of genius, however admirable, are probably nothing more than useful or profitable disease. To such strange conclusions are we led, and so are our vanities unmasked, by the frightful matter of fact of modern physiology.

Note on a contrivance for obtaining the knee-jerk more readily than by most other means. - This consists simply in "stirruping" the foot in the left hand, and adjusting the leg at the most convenient angle of flexion at the innee. The centre of the instep should be allowed to rest comfortably on the palmar aspect of the fingers and front part of the palm.

\section{HEALING BY FAITH.}

MIRACLES AT LOURDES AND OTHER PLACES; DISAPPEARANCE OF TUMOURS.

\section{BY GEORGE BUCHANAN}

PROTESSOR OF CLINICAL SURGERY, GLASGOW UNIVERSITY.

In the magazine Annales de Lourdes for July there is a notice of my article on Faith-healing in THE LANCET of June 20 th. The writer, while admitting that my explanation suffices to account for the sudden cure of such affections as I indicated-conditions simulating and presenting all the symptoms of disease of the spine, paralysis, and disease of the knee, and which he terms sine materie,-declares that nothing short of a miracle will account for the disappearance of an organic lesion, an alteration matérielle. He continues: "We do not ask that Dr. Buchanan should go back on former cases (at Lourdes); it will be better to recount a fresh one. Mdlle. D-, aged forty-four, had a tumour the size of a hen's egg in her left breast. Dr. Teuwin of Tongres certifies that in September, 1884, he diagnosed it as a cancer, causing fortes douleures. Mdlle. D- went to Lourdes, and on Jay Ist, 1885, used the water flowing from the grotto, on which she declared that the pain ceased, but the tumour remained. On the following day she again used the water, after which the tumour disappeared. On her return to Belgium she visited Dr. Teuwin, who certifies, 'I declare that to-day, May 9th, the tumour has completely disappeared." The writer of the article continues: "Have we herean organic lesion? Granted that it was not malignant; it was at least a tumour. The cure of May 2nd cannot be explained by confidence, imagination, or any impression whatever. It is a phenomenon without analogy among those which are seen in hospitals or schools of medicine." And the writer infers that it was an instance of direct divine interposition-a miraculous cure.

The easiest way of getting out of the difficulty of believing in the above statements is to assert that there must be some error or fallacy in the narrative-that the thing is impossible, and therefore did not occur as related; it is incredible, and there must be some fiaw in the story, which does not appear on the surface. I do not intend to adopt this solution.

For my own part, I hesitate to accept the evidence adduced in the Annals as satisfactory in a case of such importance as the crediblity or incrediblity of an alleged miracle. I myself would not be satisfied with anything less than a certificate as to the state of the patient immediately before and immediately after the alleged cure, given by a surgeon who, by his clinical experience and professional reputation, was recognised by the profession in his own country as an authority whose opinion could be relied on.

I distinctly disavow any intention of throwing any doubt on the sincerity of M. Teuwin. He may be a most able and skilful practitioner; but $I$ do not know of his existence. For all that the readers of the Annals know, there may be no such man. If there be, none of these readers probably ever heard of him before. My geographical ignorance is such that I do not know where Tongres is, or if there is such a place. All this I state to show that evidence which might be satisfactory to others is absolutely worthless to me, and if strictly inquired into it must be equally so to almost every, if not every, reader of the case. The truth of the cure is also alleged by the reference to a procès verbal at Lourdes; but messieurs the missionaries at Lourdes will not blame me for not accepting that as evidence. It is also stated to be contained in a letter from M. l'Abbé Demeersman, Curé of the parish of St. John the Baptist at Tongres. But M. l'Abbé will excuse me when I state that, so far as trustworthy medical evidence is concerned, $\mathrm{I}$ attach less importance to his letter than to M. Teuwin's. Altogether, I assert that, so far as the report of this case is concerned, the evidence is not sufficient for me to accept its accuracy.

But supposing the case actually did occur exactly as stated in the narrative, it is not correct to say that it is without analogy among those which are seen at hospitals. On the contrary, it is just one of the many examples of tumours spontaneously disappearing, as they sometimes do, without any treatment, to the surprise of the surgeon, who is wholly at a loss to account for the phenomenon. Adenoid tumours of the breast are those which most frequently become absorbed or removed without any apparent cause. Certain physiological changes which occur during the course of female life are well known to affect, and sometimes quite suddenly, the appearance or disappearance, the increase or diminution, of tumours apparently adenoid. But independently of such physiological actions, tumours are well known to undergo all varieties of condition without any assignable cause.

It is true that in the case of Mdlle. D — - the tumoux is alleged to have disappeared in forty-eight hours, and this is a most unusual circumstance. Still, the element of time is not so extraordinary as the actual disappearance. Even this point is left in doubt in the report. The surgeon certifies the existence of the tumour in September 1884, but does not seem to have examined it again till May $9 \mathrm{th}, 1885$, when he says he found it gone. The Curé seems to have taken the place of the medical attendant subsequently to September, 1884, and declares the tumour was in existence in April, 1885. I can scarcely believe that the Curé himself examined Mdlle. $\mathrm{D} \longrightarrow$ 's breast and gave the certificate referred to when he could have obtained a medical opinion and report if it had been desired. But, at all events, he guarantees the correctness of a certificate given by two women who seem to have been employed instead of the surgeon. The whole question of time is left obscure, or at all events without evidence satisfactory to a medical man.

But even if I go a step further, and accept the narrative as given without reservation, I still assert that it is not unique. Examples of a similar kind occur occasionally, though rarely, within the experience of most clinical surgeons. The last of the cases which follow is equally astounding and impossible of explanation. Everyone knows the effect of the nervous system on all the functions of the body, and how $\mathrm{T} 2$ 
the state of the mind influences all the processes of nutrition, absorption, secretion, \&c. It is not impossible that such a change of mental state as is involved in an intense and prolonged act of devotion directed to a particular object might so alter nerve-action and reaction as to cause absorption of a morbid growth. I do not assert that this was the cause of the disappearance of Mdlle. D___s tumour. Perhaps it is better not to attempt to account for it at all, but to content myself with relating some cases which have occurred in my own practice which bear considerable analogy to the case in point, and which to me have always been a source of wonder and wholly unable to be explained. It is not a little interesting that these cases are not related now for the first time, and with the special object of applying them to the purpose of this paper

In October, 1884, as President of the Pathological Society, I had to open the session by an address to the members. I chose as my subject certain points of interest with regard to tumours. From this address I shall give the substance of some passages and cases as bearing on the subject under consideration :-

With regard to tumours generally there are a few curious points to which I would like to refer.

1. Tumours sometimes spontaneously disappear--This is most usually observed in adenoid tumours; but it is possible that the appearances of adenoid growth might be simulated by very chronic inflammatory formation; and even tumours with all the external characteristics of scirrhus have been known to disappear.

About fifteen years ago I was consulted by the late Drs. Rainy and Peter Stewart about a lady who had a smal tumour in the breast, which $I$ believed to be scirrhus. Professor Syme gave the same opinion. The presence of the tumour caused the lady such a state of fear and nerrous dread that she presented all the appearances and symptom which are usually attributed to the "cancerous cachexia." In a few months the tumour was distinctly less, and in a year it was completely gone. She regained perfect health, and is still living in the enjoyment of it. Anyone would have said that that patient had the cancerous cachexia, which has now disappeared along with the tumour.

I once had a lady under my care who was suffering from a thyroid tumour, which was so large as to threaten suffocation from pressure on the trachea, and which extended into the root of the neck in such a way as to press on the recurrent laryngeal nerve and cause occasionally spasm of the glottis. Sir James Simpson recommended her to live near a surgeon, so that tracheotomy could be performed at once if necessary, and she came to Glasgow to live with her brother, whose residence was not far from mine. In a very few days, without any treatment, the symptoms abated, and before long the tumour diminished in size. After a few weeks it had so completely diminished as to escape notice, and she returned home in good health.

Some years ago I had in my clinical ward a young woman with a large adenoid tumour in the axilla, which by its pressure caused great pain, as also cedema of the hand and arm. The friends of the patient refused to allow her to undergo the risk of removal of the tumour from such a situation, and took her home to the Highlands. In a very short time it began to decrease in size, and $I$ subsequently learned that it entirely disappeared.

The most remarkable case with regard to suddenness occurred in connexion with a submaxillary tumour. A girl aged about twelve years, a patient in my wards, had a tumour in the submaxillary region, about the size of a small hen's egg. It was circumscribed and resistant. I thought it just possible that it might be a cystic ranula of the submaxillary gland, and to clear up any doubt I explored it with a grooved needle, but it proved to be solid. Next morning, when I went to examine it, I found it decreased so much that I could with difficulty believe that it had been there twentyfour hours before. The following day all trace of it was gone.

If this extraordinary sudden disappearance without treatment, of an undoubted solid tumour, had taken place after washing with holy water, or if it had been at Lourdes or Bethshan instead of in my surgical ward, it would have been triumphantly pointed to as an example of direct miraculous interposition. Such coincidences are sufficiently numerous to make me decline to accept the theory of divine interposition to account for some of them which take place at sacred spots, when others unquestionably occur without direct appeal to miraculous intervention, and which are equally inexplicable.

\section{NEPHROLITHOTOMY, \\ AND}

THE TREATMENT OF KIDNEYS IN AN ADVANCED STAGE OF SUPPURATION.

BY W. BRUCE CLARKE, M.B., F.R.C.S.,

ASSISTANT-SURGEON TO ST. BARTHOLOMEW'S HOSPITAL, FORMERL SURGEON TO ST. PETER'S HOSPITAL FOR DISEASES OF TEE URINARY ORGANS.

THE following case presents many points of interest, both from its clinical history and from the direction in which the pus tracked from the kidney, since it was this latter circumstance which indirectly gave rise to those symptoms which precluded the possibility of completing the exploration of the kidney with a view to nephrolithotomy.

J. L - aged forty-two, was a Imitted into St. Bartholomew's Hospital ${ }^{1}$ on April 13th, 1885, with a sinus pointing at the apex of the last rib. Three years ago she first passed some coffee-coloured urine. This continued at intervals for some months, and she suffered from considerable pain in the loins. About a year later the pain became much more violent, and then she noticed a large swelling on the right side, extending, as she says, from the hip to the armpit. Six weeks later this burst at the site of the present sinus opening. For some weeks after this she was much relieved, and able to get about, and the wound closed up; but it soon opened again, and has gone on discharging intermittently for the last eighteen months.

May 16 th. - She is a fairly well nourished woman, but has evidently lost flesh lately, and looks pale and careworn. Urine amber-coloured, sp. gr. 1022 ; deposits urates and a good deal of albumen; no blood or sugar ; it varies greatly from day to day; sometimes it is quite purulent and alkaline. Pain in the right side so severe at times that she has to keep her bed. An examination of the abdomen under ether revealed the fact that the right side was fuller than the left and gave an increased sense of resistance. She was under observation in the ward for about a month, and the symptoms underwent little or no change. A stone in the kidney was diagnosed to be the most probable cause of her suffering, and it was decided to explore the kidney, and perform neprolithotomy if possible-if not, whateveroperation seemed most likely to offer the best chance of success-when the kidney itself was laid bare. The operation was commenced by exploring the sinus, which opened at the tip of the last rib. This led underneath the ribs, and a probe passed apparently between the liver and the ribs for some five or six inches. At this stage the patient became very faint, and it was decided not to continue the operation any further that day. In the evening she complained of a great deal of pain over the region of the liver, and had a bad night.

17th. - Pain worse; breathing very catchy. Pulse irregular, 90. Friction sound could be heard over the liver. She became gradually worse, and died from symptoms of peritonitis on May 21 st, at 7 A.Mr.

Post-mortem examination.--When the skin was removed, and the sinus which had been explored was examined, it was discovered to consist of two branches. The one which had been found led, as was supposed, on to the upper surface of the liver, and its disturbance had broken through some thin peritoneal adhesions, and so had given rise to the peritonitis which had caused her death. The upper surface of the right lobe of the liver was adherent to the parietal peritoneum almost as far as the suspensory ligament, and it was close to the suspensory ligament where the peritoneal adhesions had given way. The kidney itself was surrounded by a large amount of thickened and hardened tissue, almost like cartilage, by which it was firmly attached to the neighbouring tissues and organs. The opposite kidney was about twice the natural size, and was, like all the rest of the organs, very fatty. There was a little fluid in the base of the right pleura, and indications of old and recent pleurisy. Leading out of the sinus which had been explored was a second sinus, which had not been discovered during life. This passed in a curved direction down to the centre of the kidney, and when the skin of the loin was removed a probe easily struck a calculus in the centre of the kidney. When the kidney mas

1 Was at first under Mr. Morrant Baker's care, and came under mine during his absence. 